\title{
Co-morbidity contributes to predict mortality of patients with chronic obstructive pulmonary disease
}

\author{
R. Antonelli Incalzi*, L. Fuso**, M. De Rosa**, F. Forastiere+, E. Rapiti+, \\ B. Nardecchia**, R. Pistelli**
}

Co-morbidity contributes to predict mortality of patients with chronic obstructive pulmonary disease. R. Antonelli Incalzi, L. Fuso, M. De Rosa, F. Forastiere, E. Rapiti, B. Nardecchia, R. Pistelli. CERS Journals Ltd 1997.

ABSTRACT: The aim of this study was to assess the prognostic role of co-morbidity in severe chronic obstructive pulmonary disease (COPD).

A cohort of 270 COPD patients, mean $( \pm s D)$ age $67 \pm 9$ yrs, consecutively discharged from a University Hospital after an acute exacerbation was studied. Mean ( \pm SD) forced expiratory volume in one second (FEV1) was $34 \pm 16 \%$ of predicted and $\mathrm{FEV} 1$ / forced vital capacity (FVC) was $\mathbf{4 0 . 5} \pm \mathbf{1 3 . 8 \%}$. The most common co-morbid diseas- es were: hypertension $(28 \%)$, diabetes mellitus $(14 \%)$, and ischaemic heart disease $(10 \%)$. Clinical, electrocardiogram (ECG), and respiratory function data taken at the time of discharge were collected from the clinical records. The Charlson's index was used to quantify co-morbidity. Follow-up was conducted by means of telephone calls. Multivariate survival analysis was used to identify the independent predictors of death.

The median survival of the cohort was 3.1 yrs. Death was predicted by the following variables: age (hazard rate $(H R) 1.04 ; 95 \%$ confidence intervals $(95 \% \mathrm{CI}) 1.02$ 1.05), ECG signs of right ventricular hypertrophy (HR 1.76; 95\% CI 1.30-2.38), chronic renal failure (HR 1.79; 95\% CI 1.05-3.02), ECG signs of myocardial infarction or ischaemia (HR 1.42; 95\% CI 1.02-1.96), FEV1 $<590 \mathrm{~mL}$ (HR 1.49; 95\% CI $0.97-2.27$. A score based upon these variables predicted mortality at 5 yrs with a sensitivity of $63 \%$ and a specificity of $77 \%$.

Selected co-morbid diseases and electrocardiogram signs of right ventricular hypertrophy play a major prognostic role in advanced chronic obstructive pulmonary disease. The clinical assessment of patients with chronic obstructive pulmonary disease should include these important and easily measurable variables.

Eur Respir J 1997; 10: 2794-2800.
*Dept of Geriatrics and **Dept of Respiratory Physiology Catholic University, Rome, Italy. ${ }^{+}$Latium Epidemiologic Unit, Rome, Italy.

Correspondence: L. Fuso

Fisiopatologia Respiratoria

Università Cattolica S. Cuore

Largo Francesco Vito 1

00168 Roma

Italy

Keywords: Co-morbidity

chronic obstructive pulmonary disease long-term prognosis

Received: May 271997

Accepted after revision September 281997
The determinants of life expectancy in chronic obstructive pulmonary disease (COPD) have been analysed in several studies both before and after the systematic introduction of oxygen-therapy in clinical practice [1-18]. Age and degree of airway obstruction, as reflected by forced expiratory volume in one second (FEV1), are the most commonly recognized prognostic factors [12]. Various indices of respiratory function, such as the transfer factor of the lung for carbon monoxide (TL,CO), residual volume (RV) to total lung capacity (TLC) ratio (RV/TLC), and airway hyperreactivity, add to the prognostic information provided by age and FEV1. Poor performance status, perceived physical disability, and male gender also proved to be negative correlates of survival $[10,17,19]$.

Attention has not been given to the relative prognostic role of other chronic conditions. Co-morbidity was an exclusion criterion in several studies $[2,4-6,10,16]$, while others did not provide information on co-morbid diseases or did not assess their prognostic role $[1,8,9,11,13-15$, 17-20]. Moreover, an upper age limit has frequently been adopted in selecting patients $[8,10,12,24]$. This would be expected to limit the prognostic weight of co-morbidity because ageing and co-morbidity are strongly correlated
[21]. It should also be noted that the average age of patients with COPD is increasing in parallel with that of the general population and as a result of the progressive improvement of pharmacological and nonpharmacological treatments. This trend is likely to continue in forthcoming years [22]. Thus, COPD patients, particularly those in more advanced stages of disease, can be considered a geriatric population, and co-morbidity is expected to contribute to their prognosis [23]. Furthermore, smoking history, which is an invariable finding in COPD, further predisposes these patients to co-morbidity, predominantly cardiovascular diseases, and thus might at least partially explain the negative prognostic effect of current smoking habits $[8,13,15]$. It follows that studies ignoring co-morbid diseases would provide results pertaining to a selected, but not to the general population of COPD patients.

The aim of the present study was to evaluate whether co-morbidity is a determinant of mortality and to improve the prognostic model provided by indices of severity of the disease in patients with advanced COPD receiving usual care. 


\section{Materials and methods}

\section{Subjects and data collection}

Long-term mortality from COPD was assessed in 288 consecutive patients, discharged from the Pneumology ward of the Catholic University in Rome between the years 1980-1990, after an acute exacerbation of COPD. The study protocol conformed to guidelines provided by the local ethics committee. The diagnosis of COPD was made according to the standards provided by the American Thoracic Society [24]. The acute exacerbation was defined as an increase in dyspnoea and a reduction of physical fitness, severe enough to require hospitalization. All patients were admitted through the Emergency Department. The admission procedures were re-evaluated by two doctors (LF and RP) who excluded from the study COPD patients admitted because of nonrespiratory causes. Further exclusion criteria were: coexisting near-terminal illness defined as a disease limiting the life expectancy to one month or less according to a clinical judgement $(n=18)$; major psychiatric disorders or dementia defined according to Diagnostic and Statistical Manual of Mental Disorders (DSM)- II criteria [25] $(n=4)$; participation in other medical trials $(n=12)$; clinical records providing insufficient information to meet the criteria for diagnosing co-morbid diseases [26] $(n=11)$; discharge location outside the town $(\mathrm{n}=36)$.

Multidimensional assessment was made at discharge, with the patient considered to be in a stable condition, as reported elsewhere [27]. Briefly, COPD was considered to be stabilized if the following two conditions were met for four consecutive days: 1) performance in Activities of Daily Living and severity of dyspnoea were reported by the patient to be comparable to those usual for him/her at home, prior to the acute exacerbation; and 2) arterial blood gases did not show significant changes $( \pm 5 \%)$ in the same period. These criteria were used systematically during 1980 to 1990 in order to make the data collected throughout such a long period comparable.

Co-morbid disease data were collected from clinical records. Diseases were diagnosed according to the International Classification of Health Problems in Primary Care [26]. Co-morbidity was quantified according to the Charlson Index [28, 29]. This index has been developed to predict mortality of homeliving subjects with chronic diseases. It assigns to each disease a score that is proportional to the disease-related risk of death. A score of 1 was allocated to myocardial infarction, congestive heart failure, peripheral vascular disease, cerebrovascular disease, dementia, COPD, rheumatological diseases, peptic ulcer disease, mild liver disease and diabetes. A score of 2 was attributed to diabetes with chronic complications, hemiplegia or paraplegia, renal diseases, any malignancy including leukaemia and lymphoma. Moderate or severe liver disease was assigned a score of 3 , and metastatic solid tumours and acquired immune deficiency syndrome a score of 6 . The arithmetical sum of scores of individual diseases coexisting in the same patient provides the index of co-morbidity. Thus, neither indices of COPD severity nor co-morbid conditions other than the components of the Charlson's index were recorded.
Spirometry was performed with a computerized system (HP 47-804A; Hewlett-Packard, Waltham, MA, USA), using as reference standards, those reported by KNUDSON et al. [30]. The manoeuvre had to meet the American Thoracic Society criteria for acceptability and reproducibility [31].

Arterial blood gases were measured by standard equipments (Radiometer, Copenhagen, Denmark), while the patient was breathing room air or an oxygen enriched mixture according to individual needs.

Weight and height were measured with Seca bathroom scales and a microtoise (Seca, Hamburg, Germany) fixed to the wall, respectively. Body mass index $(\mathrm{BMI})=$ weight in $\mathrm{kg} /$ height in $\mathrm{m}^{2}$ ) was computed. The electrocardiogram (ECG) at discharge was considered to be consistent with a right ventricular hypertrophy $(\mathrm{RVH})$ or overload in the presence of one or more of the following findings: type A $\mathrm{RVH}$ (dominant $\mathrm{R}$ wave in $\mathrm{V} 1$ and $\mathrm{V} 2$, $\mathrm{rS}$ pattern in V5 and V6); type B RVH (Rs pattern in V1, absent or marginal increase of R wave amplitude from V1 to V6); type $\mathrm{C}$ RVH (absent or marginal increase of $\mathrm{R}$ wave amplitude from $\mathrm{V} 1$ to $\mathrm{V} 6$, deep $\mathrm{S}$ wave in all precordial leads); S1S2S3 pattern (S wave in all bipolor leads); S1Q3 pattern (S wave in lead I, Q wave in lead III); right bundle branch block (RBBB) (QRS duration Š 0.12 s, tall and late $\mathrm{R}$ or R' wave peaking after $0.08 \mathrm{~s}$ in $\mathrm{V} 1$, and a broad and late $\mathrm{S}$ wave in leads I, V5 and V6); $\mathrm{P}$ pulmonale ( $\mathrm{P}$ wave axis $\mathrm{S}_{90^{\circ}}$ ) [32]. An ECG diagnosis of ischaemic heart disease was made if at least one of the following criteria were met: 1) signs of myocardial infarction according to the Minnesota codex [33]; 2) an ST-T elevation of depression of at least $1.5 \mathrm{~mm}$, or a negative T-wave in the absence of pharmacological and extracardiac conditions, known to affect repolarization [32]. Moreover, ST-T changes were considered nonsignificant if they occurred in leads showing QRS changes consistent with RVH. These restrictive diagnostic criteria were expected to limit the confounding effect of RVH or overload but also to reduce sensitivity of the diagnosis of myocardial ischaemia.

At the time of discharge, long-term oxygen therapy was prescribed if arterial oxygen tension $\left(\mathrm{Pa}, \mathrm{O}_{2}\right)$ was less than $7.3 \mathrm{kPa}(55 \mathrm{mmHg})$ or $8.0 \mathrm{kPa}(60 \mathrm{mmHg})$ in patients with a coexisting cardiovascular disease; oxygen enriched mixtures were delivered through a Venturi mask (Baxter, Rome, Italy).

\section{Follow-up and data analysis}

All patients were followed up for vital status from the date of discharge to June 30, 1994. Follow-up was conducted by telephone. The programmed minimum length of follow-up was $3.5 \mathrm{yrs}$, which applied to patients enrolled in the last year of the study (1990). The overall follow-up period was (mean \pm SD) $3.4 \pm 2.9 \mathrm{yrs}$, range $0-14 \mathrm{yrs}$, which reflects the very high early mortality of our patients. If it was not possible to contact patients, relatives or caregivers, the municipal register office was consulted. No information was obtained regarding 18 patients who were considered lost to follow-up; differences in baseline characteristics between patients lost to follow-up and patients studied were assessed by t-test and Chi-squared test and a p-value of less than 0.05 was considered significant. Thus, the survival analysis concerned 270 patients out of 288 and was performed using a life table analysis according to 
Kaplan-Meier. Differences in survival between subgroups of patients were assessed by Gehan's Wilcoxon test. In addition, continuous variables were analysed as risk factors for survival by Gehan's Wilcoxon test after transformation to categorical variables. Distributions of forced vital capacity (FVC), $\mathrm{FEV} 1, \mathrm{~Pa}_{\mathrm{a}} \mathrm{O}_{2}$, arterial carbon dioxide tension $\left(P \mathrm{a}, \mathrm{CO}_{2}\right)$, alveolar-arterial pressure difference for oxygen $\left(P \mathrm{~A}-\mathrm{a}, \mathrm{O}_{2}\right)$ and length of hospital stay were divided into quartiles. The risk of being in the lowest or highest quartile was assessed for FVC, FEV1, and $\mathrm{Pa}, \mathrm{O}_{2}$ or for $\mathrm{Pa}_{\mathrm{a}} \mathrm{CO}_{2}$, $P A-a, O_{2}$, and length of hospital stay, respectively. The correlation matrix of all the variables used in the survival analysis was analysed in order to check any interaction and collinearity among variables. A multivariate model of survival was obtained by the Cox regression analysis, testing only variables univariately correlated with the outcome. Age and gender as well as the year of recruitment were also tested to exclude any influence of changes in diagnostic and therapeutic procedures over time on the outcome. The proportionality assumption was graphically checked for each variable in the final model, by using stratified models.

A cumulative risk score was then obtained as follows: the variable with the highest value of $\beta$ coefficient in the multivariate model was assigned the arbitrary value of 10 ; all other variables in the model were assigned a value 10 times the ratio between its $\beta$ coefficient and the $\beta$ coefficient of the most predictive variable, as the $\beta$ coefficient is a measure of the relative contribution of each independent variable to the multivariate model [34]; each patient was then identified by a score corresponding to the sum of the values attributed to each risk factor present in that patient. A receiver operating characteristic (ROC) curve of the prognostic score versus mortality was drawn in the 228 patients with a follow-up of at least 5 yrs. The best cut-off point, i.e. the score value achieving the best discrimination between dead and surviving patients, was identified. Sensitivity and specificity of this score versus $5 \mathrm{yr}$ mortality were computed. We developed a score predicting $5 \mathrm{yr}$ mortality because the rapidly declining fraction of surviving patients would have affected the possibility of developing a prognostic score for later mortality. Furthermore, $5 \mathrm{yr}$ mortality is a measure frequently reported in previous studies, which makes the present data easily comparable.

\section{Results}

The characteristics of the population, concurrent extrapulmonary diseases, and frequency of ECG abnormalities at discharge are summarized in table 1 . The most common coexisting diseases were hypertension, diabetes mellitus and cardiac diseases, whereas the ECG signs of RVH or overload accounted for $60 \%$ of all the ECG abnormalities. The respiratory function data and the arterial gas values at the start of the follow-up are shown in table 2. A severe obstructive pattern characterized the population studied. Moreover, the high $P A-a, O_{2}$ and the high proportion of hypoxaemic and/or hypercapnic patients $(51 \%)$, even during oxygen therapy, were indicative of the average severe respiratory impairment.

By the end of the follow-up period, 228 out of 270 patients had died. The median period of survival was 1,150 days (3.1 yrs) (fig. 1). The causes of death were the
Table 1. - Selected characteristics, co-morbidity, and electrocardiographic (ECG) abnormalities among patients studied and patients lost to follow-up

\begin{tabular}{|c|c|c|}
\hline & $\begin{array}{l}\text { Patients } \\
\text { studied }\end{array}$ & $\begin{array}{l}\text { Patients } \\
\text { lost }\end{array}$ \\
\hline Number $\mathrm{M} / \mathrm{F}$ & $224 / 46$ & $13 / 5$ \\
\hline Age yrs & $67 \pm 9$ & $67 \pm 12$ \\
\hline Length of hospital stay days & $28 \pm 20$ & $32 \pm 22$ \\
\hline Coma during the hospital stay $\mathrm{n}(\%)$ & $24(9)$ & $1(6)$ \\
\hline $\begin{array}{l}\text { Mechanical ventilation during the } \\
\text { hospital stay } \mathrm{n}(\%)\end{array}$ & 44 (16) & $2(11)$ \\
\hline Diabetes mellitus n (\%) & $39(14)$ & $3(17)$ \\
\hline Hypertension $\mathrm{n}(\%)$ & $75(28)$ & $4(22)$ \\
\hline Chronic renal failure $\mathrm{n}(\%)$ & $17(6)$ & $2(11)$ \\
\hline Chronic liver disease $\mathrm{n}(\%)$ & $17(6)$ & $1(6)$ \\
\hline Cerebrovascular disease $\mathrm{n}(\%)$ & $9(3)$ & 0 \\
\hline Ishaemic heart disease $\mathrm{n}(\%)$ & $28(10)$ & $2(11)$ \\
\hline History of myocardial infarction $\mathrm{n}(\%)$ & $11(4)$ & $1(6)$ \\
\hline Charlson's co-morbidity index ${ }^{\dagger}$ & $1.38 \pm 0.67$ & $1.50 \pm 0.62$ \\
\hline Age-co-morbidity index ${ }^{+}$ & $3.65 \pm 1.25$ & $3.89 \pm 1.37$ \\
\hline ECG signs of RVH or overload n (\%) & $163(60)$ & $10(56)$ \\
\hline $\begin{array}{l}\text { ECG signs of ischaemic heart } \\
\text { disease } \mathrm{n}(\%)\end{array}$ & $58(21)$ & $8(44)^{*}$ \\
\hline $\begin{array}{l}\text { ECG evidence of ventricular } \\
\text { arrhythmias } \mathrm{n}(\%)\end{array}$ & $17(6)$ & 0 \\
\hline
\end{tabular}

Values are presented as mean $\pm S D$, or as absolute number with percentage in parenthesis. M: male; F: female; RVH: right ventricular hypertrophy. $*$ : $\mathrm{p}<0.05$, chi-squared test; ${ }^{\dagger}$ : see [28]; ${ }^{+}$: see [29].

Table 2. - Respiratory function data and arterial gas values at the start of follow-up in the patients studied

\begin{tabular}{lc}
\hline FVC L & $2.11 \pm 0.64$ \\
FVC \% pred & $64.4 \pm 17.4$ \\
FEV 1 L & $0.84 \pm 0.37$ \\
FEV $1 \%$ pred & $34.1 \pm 16.1$ \\
$\mathrm{FEV} 1 / \mathrm{FVC} \%$ & $40.5 \pm 13.8$ \\
$P_{\mathrm{a}, \mathrm{O}_{2}} \mathrm{kPa}$ & $8.5 \pm 1.3$ \\
$P \mathrm{a}, \mathrm{CO}_{2} \mathrm{kPa}$ & $6.0 \pm 1.1$ \\
$\mathrm{pH}$ & $7.40 \pm 0.04$ \\
$P \mathrm{~A}-\mathrm{a}, \mathrm{O}_{2} \mathrm{kPa}$ & $4.8 \pm 2.0$ \\
\hline
\end{tabular}

Values are presented as mean $\pm S D$. Arterial gas values were measured while the patients breathed room air or oxygenenriched mixtures at concentrations ranging $24-35 \%$, according to the individuals needs. FVC: forced vital capacity; FEV1: forced expiratory volume in one second; $\mathrm{Pa}_{\mathrm{a}} \mathrm{O}_{2}$ : arterial oxygen tension; $\mathrm{Pa}_{\mathrm{a}} \mathrm{CO}_{2}$ : arterial carbon dioxide tension; $P \mathrm{~A}-\mathrm{a}, \mathrm{O}_{2}$ : alveolar-arterial oxygen difference. $1 \mathrm{kPa}=7.52 \mathrm{mmHg}$.

following: COPD in 144 patients, cardiovascular disease in 36 patients; lung cancer diagnosed after discharge in 11 patients; other neoplastic diseases diagnosed after discharge in nine patients; other causes of death in six patients; and unknown causes in 22 patients.

Table 3 shows the significant correlates of mortality according to the univariate analysis. A $P A-a, O_{2} \breve{S} 5.4 \mathrm{kPa}$ $(40.8 \mathrm{mmHg})$ corresponding to the highest quartile of $\mathrm{PA}-\mathrm{a}, \mathrm{O}_{2}$ distribution, while the patient was breathing air or an oxygen-enriched mixture at the prescribed oxygen concentration, was the strongest correlate of mortality and preceded chronic renal failure and ECG signs of RVH or overload. An FEV1 $<590 \mathrm{~mL}$ corresponding to the lowest quartile of FEV1 distribution, a length of hospital stay Š33 days, corresponding to the highest quartile of the length- 


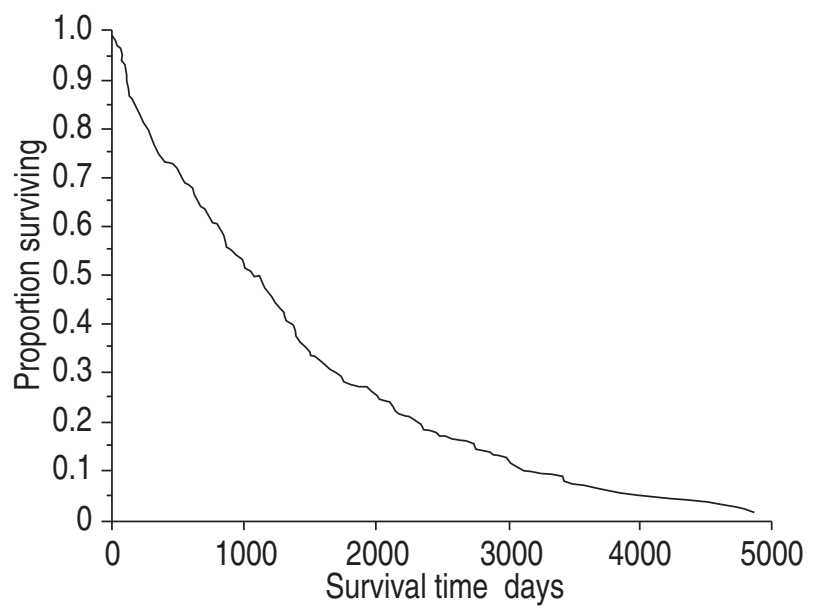

Fig. 1. - Cumulative survival rate of the population studied.

of-stay distribution, ECG signs of ischaemic heart disease, chronic liver disease, ECG evidence of ventricular arrhythmias, and a history of acute myocardial infarction were weaker correlates of mortality.

Results from the correlation matrix excluded collinearity, that is a prognostic effect partially shared by highly intercorrelated independent variables, between FEV1 and $\mathrm{RVH}$ as well as between $\mathrm{FEV} 1$ and $P \mathrm{~A}-\mathrm{a}, \mathrm{O}_{2}$, as predictors of death. It should be observed that these data refer to usual blood gases, i.e. to those measured during oxygen therapy if prescribed, in order to correct results for the possible influence of oxygen therapy on survival $[5,6]$.

The following five variables, in order of decreasing magnitude with respect to their $\beta$ coefficient, were identified by multivariate analysis as independent significant correlates of mortality (table 4): chronic renal failure, ECG signs of RVH or overload, FEV $1<590 \mathrm{~mL}$, ECG signs of ischaemic heart disease and age. In force of their collinearity, some variables were correlated with the outcome in the univariate but not in the multivariate analysis. For example, a $\mathrm{PA}-\mathrm{a}, \mathrm{O}_{2}$ of $\mathrm{S} 5.4 \mathrm{kPa}(40.8 \mathrm{mmHg})$, which was significantly correlated with mortality at univariate analysis characterized $69.5 \%$ of patients with ECG signs of RVH who ultimately died. Thus, the relationship between RVH and mortality concealed that between $\mathrm{PA}-\mathrm{a}, \mathrm{O}_{2}$ and mortality. Moreover, no variable lacking predictivity in the univariate analysis was a significant predictor of death according to the multivariate procedure.

The score assigned to each variable significantly correlated with death at the multivariate analysis is shown in table 5. As previously stated, the score attributed to "chronic renal failure", the variable having the highest $\beta$ coefficient, was assumed to be 10 . Given that age was a continuous and not a categorical variable, the corresponding score (0.62) was multiplied by the age (in years) of each patient. Figure 2 shows the ROC curve of the proposed score of COPD severity versus mortality. The best cut-off point identified on the ROC curve had a sensitivity

Table 3. - Survival of patients with chronic obstructive pulmonary disease, according to various characteristics

\begin{tabular}{|c|c|c|c|c|}
\hline \multirow{2}{*}{$\begin{array}{l}\text { Variables significantly correlated } \\
\text { with mortality }\end{array}$} & \multicolumn{2}{|c|}{ Survival yrs } & \multirow[t]{2}{*}{ Gehan's Wilcoxon } & \multirow[t]{2}{*}{$\mathrm{p}$-value } \\
\hline & Presence of risk & Absence of risk & & \\
\hline$\overline{P A-a, O_{2}}{ }^{+}$ & $1.76(0.29-4.25)$ & $3.29(1.46-5.04)$ & 3.071 & 0.001 \\
\hline Chronic renal failure & $0.84(0.25-2.35)$ & $3.17(1.29-4.99)$ & 2.917 & 0.002 \\
\hline ECG signs of RVH or overload & $2.62(0.89-4.35)$ & $3.50(1.06-5.53)$ & 2.371 & 0.009 \\
\hline $\mathrm{FEV}_{1} \dagger^{\circ}$ & $2.88(0.73-4.79)$ & $3.89(2.35-5.80)$ & 2.235 & 0.012 \\
\hline Length of hospital stay ${ }^{+}$ & $2.23(0.65-4.57)$ & $3.36(1.39-5.04)$ & 2.195 & 0.014 \\
\hline ECG signs of ischaemic heart disease & $2.19(0.69-3.97)$ & $3.26(1.27-5.21)$ & 1.913 & 0.027 \\
\hline Chronic liver disease & $1.45(0.33-3.76)$ & $3.11(1.04-5.04)$ & 1.839 & 0.033 \\
\hline ECG evidence of ventricular arrhythmias & $2.39(0.48-3.45)$ & $3.12(0.98-5.04)$ & 1.822 & 0.034 \\
\hline History of myocardial infarction & $0.84(0.50-3.20)$ & $3.12(1.14-5.02)$ & 1.738 & 0.041 \\
\hline
\end{tabular}

Survival values are presented as median values with interquartile ranges in parentheses. $P_{\mathrm{A}-\mathrm{a}, \mathrm{O}_{2}}$ : alveolar-arterial oxygen difference; ECG: electrocardiogram; RVH: right ventricular hypertrophy; FEV1: forced expiratory volume in one second. ${ }^{\dagger}$ : lowest quartile versus other quartiles; ${ }^{+}$: highest quartile versus other quartiles.

Table 4. - Results of the multivariate Cox regression analysis

\begin{tabular}{lcccc}
\hline \multicolumn{1}{c}{ Variables } & $\beta$ coefficient & Hazard rate (95\% CI) & t-value & p-value \\
\hline Age (per year) & 0.038 & $1.04(1.02-1.05)$ & 4.88 & 0.00001 \\
ECG signs of RVH or overload & 0.565 & $1.76(1.30-2.38)$ & 3.67 & 0.0003 \\
Chronic renal failure & 0.580 & $1.79(1.05-3.02)$ & 2.16 & 0.032 \\
ECG signs of ischaemic heart disease & 0.349 & $1.42(1.02-1.96)$ & 2.10 & 0.037 \\
FEV ${ }^{\dagger}$ & 0.398 & $1.49(0.97-2.27)$ & 1.97 & 0.049 \\
Chronic liver disease & 0.508 & $1.66(0.95-2.88)$ & 1.80 & 0.073 \\
ECG evidence of ventricular arrhythmias & 0.470 & $1.60(0.93-2.75)$ & 1.70 & 0.089 \\
${\text { AA-a, }{ }_{2}^{+}}^{+}$ & 0.231 & $1.26(0.92-1.72)$ & 1.44 & 0.149 \\
Length of hospital stay $^{+}$ & 0.124 & $1.13(0.83-1.55)$ & 0.77 & 0.441 \\
Year of recruitment & -0.016 & $0.98(0.94-1.03)$ & -0.72 & 0.471 \\
Female gender & -0.031 & $0.97(0.67-1.41)$ & -0.16 & 0.869 \\
History of myocardial infarction & 0.053 & $1.05(0.54-2.05)$ & 0.15 & 0.876 \\
\hline
\end{tabular}

95\% CI: 95\% confidence intervals; ECG: electrocardiogram; RVH: right ventricular hypertrophy; FEV1: forced expiratory volume in one second; $\mathrm{PA}-\mathrm{a}, \mathrm{O}_{2}$ : alveolar-arterial oxygen difference. ${ }^{\dagger}$ : lowest quartile versus other quartiles; ${ }^{+}$: highest quartile versus other quartiles. 
Table 5. - Prognostic score attributed to each variable significantly correlated with mortality at the multivariate analysis

\begin{tabular}{lc}
\hline \multicolumn{1}{c}{ Variable } & Score \\
\hline Chronic renal failure & 10 \\
ECG signs of RVH or overload & 9.7 \\
FEV1 <590 mL & 6.7 \\
ECG signs of ischaemic heart disease & 5.7 \\
Age $^{+}$ & 0.62 \\
\hline
\end{tabular}

ECG: electrocardiogram; RVH: right ventricular hypertrophy; FEV1: forced expiratory volume in one second. Score: arithmetical sum of scores assigned to individual variable. ${ }^{+}$: age as a continuous and not a categorical variable, the corresponding value ( 0.62$)$ was multiplied by the age of each patient (in years).

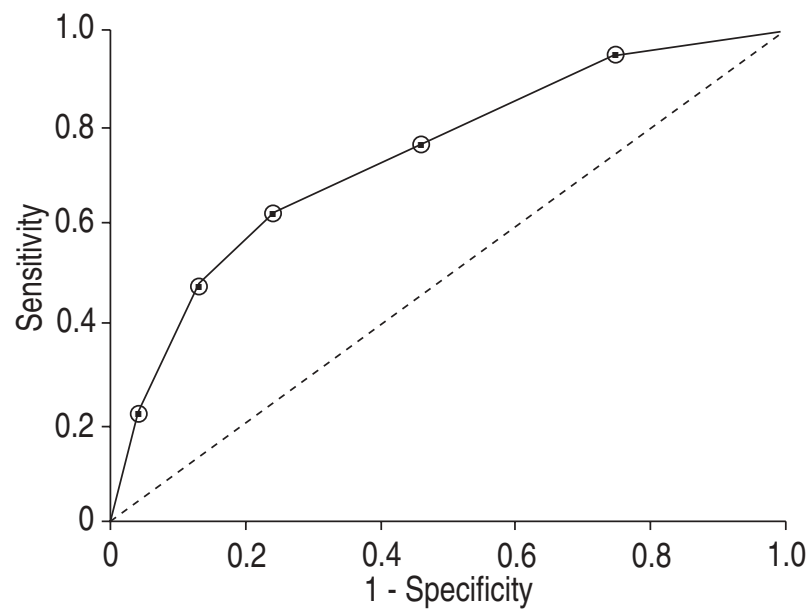

Fig. 2. - Receiver operating characteristic (ROC) curve of the proposed score of chronic obstructive pulmonary disease (COPD) severity versus 5 yr mortality. The area under the ROC curve is directly proportional to the discriminatory ability of the predictive score.

of $63.4 \%$ and a specificity of $76.6 \%$ versus $5 \mathrm{yr}$ mortality and corresponded to a score value of 48 . Thus, the proposed score could effectively identify patients at risk of death.

\section{Discussion}

This study shows that both renal failure and ischaemic heart disease were highly relevant to the prognosis of COPD patients discharged from hospital after an acute exacerbation. These co-morbid diseases probably acted as markers of frailty by increasing the fatality rate of further COPD exacerbations. On the other hand, a comprehensive index of co-morbidity, such as the Charlson's index, lacked predictive ability. The Charlson's index was developed to measure co-morbidity in a population discharged from an acute care hospital. Both the original index and the combined age and co-morbidity index proved to have prognostic implications in out-patients with chronic diseases and in a geriatric population [28, 29]. The lack of predictivity of these indices suggests that selected diseases can affect the prognosis of advanced COPD, while most diseases taken into consideration to compute the comorbidity index did not improve the prognostic model. This is the case in hypertension and diabetes mellitus, which were the most prevalent co-morbid diseases. Thus, efforts should be made to develop an index of co-morbidity tailored to the COPD population. However, it cannot be excluded that the Charlson's index of co-morbidity might apply to patients with mild to moderate COPD. Indeed, the effect on survival of co-morbid diseases carrying a relatively low risk of death is expected to be stronger in patients in the early stages of COPD. Finally, it is worth observing that chronic renal failure and myocardial infarction are components of both the Charlson's index of comorbidity and the proposed prognostic score, but only the latter had predictive ability. At least three reasons account for the differences in predictive ability: 1) only myocardial infarction contributes in the computation of the Charlson's index, whereas the proposed prognostic score also takes into account ECG signs of ischaemic heart disease; 2) the relative weight of a given disease in each of the two indices varies, e.g. chronic renal failure is the most important component of the proposed index, as reflected by the assigned score, while having an intermediate score in the Charlson's index; and 3) most importantly, it would not be correct to compare an index of co-morbidity with a prognostic score. Indeed, the latter also takes into account indices of COPD severity that are not included in the former.

ECG signs of RVH or overload were the second most important predictor of death. This is an important finding, because these indexes are very simple and easy to measure. They probably target patients with severe pulmonary hypertension and cor pulmonale, which have been shown to be a risk factor for mortality $[9,16]$. On a small series of COPD patients, BuRRows et al. [35] showed that survival is inversely related to pulmonary hypertension, and that pulmonary hypertension and clinical features of cor pulmonale characterize patients with ECG signs of RVH. Our findings confirm that the development of chronic cor pulmonale represents a turning-point in the course of COPD [16]. Moreover, the lack of a significant correlation between FEV1 and RVH suggests that chronic cor pulmonale characterizes only a fraction of patients with severe airways obstruction and that it qualifies as an autonomous marker of COPD severity.

Blood gases lacked predictive ability although the regular use of oxygen therapy is expected to limit the consequences of abnormal gas exchange on survival $[5,6]$. Some previous studies recognized hypoxaemia and/or hypercapnia as predictors of death $[2,6,8,15,16]$, while others did not $[9,11,17]$; others disclosed an association between hypercapnia and survival, possibly because some degree of hypoventilation and decreased respiratory work characterizes hypercapnic patients $[9,18,36]$. However, hypercapnia might also be due to pump failure and, in this case, qualify as a negative prognostic factor [18]. Probably, the complex and variable physiopathological meaning of hypercapnia, as well as the restriction of $\mathrm{Pa}, \mathrm{O}_{2}$ values to a narrow range due to oxygen therapy, accounted for the nonsignificant relationship between blood gases and survival.

The present study confirms the leading prognostic role of age in COPD [12]. This probably reflects both the agerelated increase in severity of COPD and the direct relationship among age, co-morbidity and frailty.

The predictive power of FEV1 was also confirmed, but other variables were stronger predictors of death. The relatively narrow range of FEV1 values in patients with 
advanced COPD probably accounts for this finding. Overlooking co-morbidity is also likely to have enhanced the predictive power of FEV1 in previous studies.

The proposed predictive model had a sensitivity of $63.4 \%$ and a specificity of $76.6 \%$ : It cannot be excluded that a more defined scoring system could improve predictivity. However, it was our intention to construct a simple and easily applicable prognostic tool. A correct methodological approach implies that a prognostic score be derived from an independent population (training population) and then be tested on the study population (testing population). The latter phase of the study will definitively clarify usefulness and limits of the proposed predictive score.

Limitations of this study should be mentioned. The loss to follow-up of 18 patients limits the strength of the conclusions. However, as reported in table 1, age, gender and co-morbidity distribution in these patients were similar to the studied population, thus suggesting that no plausible bias could derive from missing informations. Given that most of the present patients regularly attended specialized out-patient respiratory departments, uncertainty exists as to whether the present findings are common to the general COPD population. Moreover, the present data were derived from patients with severe COPD and thus cannot be applied to the overall population of COPD patients. Uncertainty exists about the cause of death in 22 patients. This prevented detailed analysis of the relationship between risk factors and causes of death. Patients did not benefit from any programme of home care and surveillance. Thus, compliance with drugs and oxygen therapy was not systematically assessed. This, and the lack of attention to mental and performance status, prevented the collection of variables potentially relevant to the improvement of the prognostic model.

These limitations do not weaken the main conclusion of the present study: co-morbid conditions and electrocardiogram signs of right ventricular hypertrophy are important prognostic variables in advanced chronic obstructive pulmonary disease. Efforts should be made to further characterize the spectrum of co-morbid diseases and to assess their prognostic role in the earlier stages of chronic obstructive pulmonary disease. The physiopathological and clinical bases of the relationship between electrocardiogram signs of right ventricular hypertrophy and death should be clarified. The prevalent type of respiratory disease, i.e. bronchitic or emphysematous, should also be identified, because it might have prognostic relevance $[18,20]$. Being aware of the full spectrum of risk factors in chronic obstructive pulmonary disease will allow improved management and the planning of formal support to a wide range of chronically ill patients with important and peculiar needs for care.

\section{References}

1. Burrows B, Earl RH. Course and prognosis of chronic obstructive lung disease. N Engl J Med 1969; 280: 397404.

2. Boushy SF, Thompson HK, North LB, Beale AR, Snow TR. Prognosis in chronic obstructive pulmonary disease. Am Rev Respir Dis 1973; 108: 1373-1383.

3. Gottlieb LS, Balchum OJ. Course of chronic obstructive pulmonary disease following first onset of respiratory failure Chest 1973; 63: 5-8.

4. Postma DS, Burema J, Gimeno F, et al. Prognosis in severe chronic obstructive pulmonary disease. Am Rev Respir Dis 1979; 119: 357-367.

5. Nocturnal Oxygen Therapy Trial Group. Continuous or nocturnal oxygen therapy in hypoxemic chronic obstructive lung disease: a clinical trial. Ann Intern Med 1980; 93: 391-398.

6. Medical Research Council Working Party. Long-term domiciliary oxygen therapy in chronic hypoxic cor pulmonare complicating chronic bronchitis and emphysema. Lancet 1981; i: 681-686.

7. Martin TR, Lewis SW, Albert RK. The prognosis of patients with chronic obstructive pulmonary disease after hospitalization for acute respiratory failure. Chest 1982; 82: 310-314.

8. Kanner RE, Renzetti AD, Stanish WM, Barkman HW, Klauber MR. Predictors of survival in subjects with chronic airflow limitation. Am J Med 1983, 74: 249-255.

9. Keller R, Ragaz A, Borer P. Predictors of early mortality in patients with long-term oxygen home therapy. Respiration 1985; 48: 216-221.

10. Anthonisen NR, Wright EC, Hodgkin JE, and the IPPB Trial Group. Prognosis in chronic obstructive pulmonary disease. Am Rev Respir Dis 1986; 133: 14-20.

11. Cooper CB, Waterhouse J, Howard P. Twelve years clinical study of patients with hypoxic cor pulmonale given long-term domiciliary oxygen therapy. Thorax 1987; 42: $105-110$.

12. Anthonisen NR. Prognosis in chronic obstructive pulmonary disease: results from multicenter clinical trials. $A m$ Rev Respir Dis 1989; 140: S95-S99.

13. Postma DS, Sluiter HJ. Prognosis of chronic obstructive pulmonary disease: the Dutch experience. Am Rev Respir Dis 1989; 140: S100-S105.

14. Dubois P. Machiels J, Smeets F, Delwiche JP, Lulling J. $\mathrm{CO}$ transfer capacity as a determining factor of survival for severe hypoxaemic COPD patients under long-term oxygen therapy. Eur Respir J 1990; 3: 1042-1047.

15. Strom K, Boe J, and the Swedish Society of Chest Medicine. Quality assessment and predictors of survival in long-term domiciliary oxygen therapy. Eur Respir $J$ 1991; 4: 50-58.

16. Skwarski K, MacNee W, Wraith PK, Sliwinski P, Zielinski J. Predictors of survival in patients with chronic obstructive pulmonary disease treated with long-term oxygen therapy. Chest 1991; 100: 1522-1527.

17. Strom K. Survival of patients with chronic obstructive pulmonary disease receiving long-term domiciliary oxygen therapy. Am Rev Respir Dis 1993; 147: 585-591.

18. Dubois P, Jamart J, Machiels J, Smeets F, Lulling J. Prognosis of severely hypoxemic patients receiving long-term oxygen therapy. Chest 1994; 105: 469-474.

19. Miyamoto K, Aida A, Nishimura M, Aiba M, Kira S, Kawakami Y, and the Respiratory Failure Research Group in Japan. Gender effect on prognosis of patients receiving long-term home oxygen therapy. Am J Respir Crit Care Med 1995; 152: 972-976.

20. Burrows B, Bloom JW, Traver GA, Cline MG. The course and prognosis of different forms of chronic airways obstruction in a sample from the general population. N Engl J Med 1987; 317: 1309-1314.

21. Schellevis FG, Van der Velden J, Van de Lisdonk E, Van Eijk JThM, Van Weel C. Co-morbidity of chronic diseases in general practice. J Clin Epidemiol 1993; 46: 469-473.

22. Siafakas NM, Vermeire P, Pride NB, et al. Optimal assessment and management of chronic obstructive pulmonary 
disease (COPD). Eur Respir J 1995; 8: 1398-1420.

23. Fuso L, Antonelli Incalzi R, Pistelli R, et al. Predicting mortality of patients hospitalized for acutely exacerbated chronic obstructive pulmonary disease. Am J Med 1995; 98: 272-277.

24. American Thoracic Society. Standards for the diagnosis and care of patients with chronic obstructive pulmonary disease. Am J Respir Crit Care Med 1995; 152: S77S120.

25. American Psychiatric Association. Diagnostic and statistical manual of mental disorders. 3rd ed. Washington, APA, 1988.

26. Classification Committee of WONCA International classification of health problems in primary care (ICHPPC)2-defined. 3rd ed. Oxford, Oxford University Press, 1983.

27. Antonelli Incalzi R, Pistelli R, Fuso L, Cocchi A, Bonetti MG, Giordano A. Cardiac arrhythmias and left ventricular function in respiratory failure from chronic obstructive pulmonary disease. Chest 1990; 97: 1092-1097.

28. Charlson ME, Pompei P, Ales KL, MacKenzie CR. A new method of classifying prognostic comorbidity in longi-tudinal studies: development and validation. $J$ Chron Dis 1987; 40: 373-383.

29. Charlson M, Szatrowski TP, Peterson J, Gold J. Validation of a combined comorbidity index. J Clin Epidemiol
1994; 47: 1245-1251.

30. Knudson RJ, Slatin RC, Lebowitz MD, Burrows B. The maximal expiratory flow-volume curve. Normal standards, variability, and effects of age. Am Rev Respir Dis 1976; 113: 587-600.

31. American Thoracic Society. Snowbird workshop on standardization of spirometry. Am Rev Respir Dis 1979; 119: 831-838.

32. Fisch C. Electrocardiography and vectorcardiography. In: Braunwald E ed. Heart disease. 4th ed. Philadelphia, WD Saunders, 1992; pp. 116-160.

33. Blackburn H, Keys A, Simonson E, Rautahagu P, Punsar $\mathrm{S}$. The electrocardiogram in population studies. A classification system. Circulation 1960; 21: 1160-1175.

34. Snedecor GW, Cochran WG. Statistical methods. 8th ed. Ames, Iowa State University Press, 1989; pp. 333373.

35. Burrows B, Kettel LJ, Niden AH, Rabinowitz M7 Diener CF. Patterns of cardiovascular dysfunction in chronic obstructive lung disease. N Engl J Med 1972; 286: 912918.

36. Ashutosh K, Dunsky M. Non invasive tests for responsiveness of pulmonary hypertension to oxygen. Prediction of survival in patients with chronic obstructive lung disease and cor pulmonale. Chest 1987; 92: 392-399. 